Helena Gil-Campesino ${ }^{1}$

Laura Sante ${ }^{1}$

Enrique Callejas Castro²

María Lecuona

\title{
Introduction of a complementary screening system for the detection of sexually transmitted infections in patients with sterile pyuria
}

\author{
'Department of Microbiology and Infection Control, University Hospital of the Canary Islands, Santa Cruz de Tenerife \\ Spain. \\ ${ }^{2}$ University of La Laguna, San Cristóbal de La Laguna, Santa Cruz de Tenerife, Spain.
}

Article history

Received: 28 November 2020; Revision Requested: 7 January 2021; Revision Received: 17 January 2021; Accepted: 1 February 2021; Published: 5 April 2021

\section{ABSTRACT}

Objective. The aim of the study was to evaluate a complementary screening system for the detection of sexually transmitted infections in patients with sterile pyuria.

Material and methods. A prospective study was conducted using Real-time multiplex qPCR in 300 consecutive urine samples with data on sterile pyuria. STI prevalence and patient epidemiological data were analyzed.

Results. A total of 29 positive cases (9.67\%) were found: 16 Chlamydia trachomatis, 5 Mycoplasma genitalium, 5 Trichomonas vaginalis and 3 co-infections. The group with sexually transmitted infections was mainly composed of women (65.5\%), of which one third was pregnant.

Conclusion. This study presents an effective screening system for the detection of sexually transmitted infections that can be integrated into the laboratories' work routine.

\section{Introducción de un sistema de cribado complementario para la detección de infecciones de transmisión sexual en pacientes con piuria estéril}

\section{RESUMEN}

Objetivo. El objetivo del estudio fue evaluar un sistema de cribado complementario para la búsqueda de infecciones de transmisión sexual en pacientes con piuria estéril.

Material y métodos. Se realizó un estudio prospectivo mediante qPCR multiplex a tiempo real en 300 orinas consecutivas de a las que se les solicitaba cultivo con datos de piuria

Correspondence:

Helena Gil-Campesino

Department of Microbiology and Infection Control, University Hospital of the Canary Islands. Ctra. del Rosario, 115, 38010 Santa Cruz de Tenerife, Spain.

E-mail: hgilcam@gobiernodecanarias.org estéril. Se analizó la prevalencia de ITS y los datos epidemiológicos de los pacientes.

Resultados. Se encontraron un total de 29 casos positivos (9,67\%): 16 Chlamydia trachomatis, 5 Mycoplasma genitalium, 5 Trichomonas vaginalis y 3 coinfecciones. El grupo con resultado positivo estaba formado mayoritariamente por mujeres $(65,5 \%)$, de las cuales un tercio estaban embarazadas.

Conclusiones. Este estudio presenta un sistema de cribado efectivo para la detección de infecciones de transmisión sexual y se puede integrar de forma complementaria en la rutina de los laboratorios.

\section{INTRODUCTION}

Sexually transmitted infections (STIs) are one of the most common public health problems [currently in existence] due to their high prevalence, morbidity and medium-and longterm sequelae. According to the World Health Organization, there are an estimated 357 million new STls every year among people aged $15-49$ years $[1,2]$. These infections cause serious diseases (e.g., vaginitis, cervicitis, proctitis), chronic and severe complications (e.g., pelvic inflammatory disease, ectopic pregnancies, neonatal death) and increase the risk of HIV transmission [3].

Although STIs screening is usually carried out through anamnesis in primary healthcare and infectious diseases centers, the implementation of complementary screening methods integrated into the routine of hospitals remains a challenge. An active search system could be developed in microbiology departments through the detection of sterile pyuria, as this alteration is sometimes caused by STIs [4-6]. Sterile pyuria is defined as the presence of $>10$ leukocytes per field in urine in the absence of a demonstrable urinary tract infection (UTI), as determined by means of aerobic laboratory techniques (on a 5\% sheep-blood agar plate and MacConkey agar plate), discarding the use of previous antibiotics [4]. This system would 
be applied to the urine of patients who have been collected by routine checks (e.g. pregnant) or patients with possible urinary tract infection (UTI) in which sterile pyuria is detected and no UTI is demonstrated in which no STI is suspected by the clinician, since the differential diagnosis between UTI and STIs can often be difficult given the similarity in the clinic and because both share abnormalities in the urinalysis $[7,8]$.

This complementary screening can help improve diagnosis and reduce the use of inappropriate antibiotic treatments that have significant negative effects (e.g. development of microbial resistance, adverse reactions, secondary infections) [9]. An analysis of the profile of those patients who present a positive result could help to develop recommendations on the application of such screenings, as very few studies can be found on the incidence of STIs in patients with sterile pyuria $[4,10,11]$.

The objectives of the present study were: 1) to study the incidence of STIs in patients with sterile pyuria using real-time multiplex $\mathrm{PPCR} ; 2$ ) to compare the epidemiological variables and urine parameters of patients with positive and negative results and 3 ) to determine whether the midstream urine samples used for bacteriological culture are valid for the detection of STI-producing microorganisms.

\section{MATERIAL AND METHODS}

A prospective study was conducted between August and November 2019 at the Complejo Hospitalario Universitario de Canarias. The patients came from primary healthcare centers and/or the emergency department. The inclusion criteria were: 1) Aged 18-55 years; 2) negative urine culture and leukocyte-esterase positive (SediMAX ${ }^{\circledR}, 77$ Elektronika); 3) not having received recent antibiotic treatment.
Real-time qPCR (Anyplex ${ }^{\mathrm{TM}}$ IISTI-7 detection, Seegene) was performed in urines with sterile pyuria that met the inclusion criteria. If qPCR was not performed on the same day, the urine was frozen at $-80^{\circ} \mathrm{C}$. The presence of the following microorganisms was analyzed: Chlamydia trachomatis, Neisseria gonorrhoeae, Trichomonas vaginalis and Mycoplasma genitalium. The qPCR also detected the presence of Mycoplasma hominis, Ureaplasma urealyticum and Ureaplasma parvum but, because these microorganisms can colonize the genital tract, they were not included in the study. When a positive result was obtained, it was recommended to send a new sample (genital exudate or first voided urine) before starting antibiotic treatment as well as serological screening for other STIs.

For the third goal of the study, in those patients who also provided a sample of genital exudate or the first $20-30 \mathrm{~mL}$ of the urine stream, this same gPCR was performed and compared with the results of the midstream urine samples used for bacteriological culture.

The following epidemiological data were collected: sex, age, pregnancy, previous history of other STIS (HCV, HBV, HIV and / or syphilis) and urine parameters: leukocytes, nitrites and red blood cells.

To study the incidence of STIs, an analysis was carried out with descriptive statistics. To compare epidemiological variables and urine parameters, contingency analysis (chi-square statistic test) was performed for categorical variables and Student's t-test for quantitative variables. Finally, to determine whether the midstream urine was valid for the detection of STI-producing microorganisms, the concordance between the samples sent in parallel was analyzed by studying the Cohen kappa coefficient. The IBM SPSS V22 program was used for data analysis.

\begin{tabular}{|c|c|c|c|c|}
\hline \multirow{4}{*}{$\begin{array}{l}\text { Table } 1 \\
\text { Variable }\end{array}$} & \multicolumn{4}{|c|}{$\begin{array}{l}\text { Comparison of patient groups of epidemiological data and } \\
\text { urine parameters with positive qPCR result vs negative } \\
\text { result }(N=300) \text {. }\end{array}$} \\
\hline & \multicolumn{2}{|c|}{ Group } & \multirow[t]{3}{*}{$t / x^{2}$} & \multirow[t]{3}{*}{$p$} \\
\hline & Positive (29) & Negative (271) & & \\
\hline & $\% / A v$. (SD) & $\% / A v$. (SD) & & \\
\hline Sex (Female) & $65.5 \%$ & $95.9 \%$ & 37.25 & $<0.001$ \\
\hline Age & $29.93(10.34)$ & $33.92(9.66)$ & 2.10 & 0.037 \\
\hline Pregnant (yes) & $28.8 \%$ & $42.1 \%$ & 1.49 & 0.222 \\
\hline Nitrites (positive) & $0.7 \%$ & $3.4 \%$ & 1.94 & 0.16 \\
\hline Red blood cells (positive) & $23.6 \%$ & $20.7 \%$ & 0.13 & 0.72 \\
\hline Leukocytes & & & 9.61 & 0.008 \\
\hline Low & $41.4 \% \%^{\mathrm{a}}$ & $67.9 \% \%^{\mathrm{a}}$ & & \\
\hline Medium & $27.6 \%$ & $19.2 \%$ & & \\
\hline High & $31.0 \% \%^{\mathrm{a}}$ & $12.9 \% \%^{\mathrm{a}}$ & & \\
\hline
\end{tabular}

Significant corrected typified residuals $\left(-1.96>\mathrm{r}_{\mathrm{z}}>1.96\right)$. 


\section{RESULTS}

A total of 8,453 urines received for urine culture showed sediment, of which 11\% (927) had sterile pyuria. Of these, 300 met the inclusion criteria. The sample consisted mostly of women (93\%) with a mean age of $33.9 \pm 9.66$ years, of whom one third were pregnant (29.75\%). With regard to the urinary parameters analyzed of the 300 samples included in the study, a total of $1 \%$ of urine with positive nitrates and $23.33 \%$ with positive red blood cells were obtained. $65.3 \%$ had a low white blood cell level (<20 WBC/HPF), 20\% had a medium level (20$60)$ and $14.7 \%$ had a high level ( $>60)$.

qPCR was positive in 29 patients (9.67\% of the samples), of which 16 had C. trachomatis (5,33\%), 5 M. genitalium $(1,66 \%), 5$ T. vaginalis $(1,66 \%)$. In addition, 1 patient presented $C$. trachomatis co-infection with $N$. gonorrhoeae $(0,33 \%)$, other with $T$. vaginalis $(0,33 \%)$ and other with $M$. genitalium $(0,33 \%)$.

With respect to the comparison between patients diagnosed with STIs and those for which qPCR was negative, patients with a positive result for any of the microorganisms studied were characterized by having a lower mean age and being found within a lower percentage of women and pregnant women (Table 1), besides there being a higher percentage of high leukocytes compared to patients with negative result $\left(r_{z}=2.6\right)$. In addition, a lower percentage of low leukocytes was recorded in patients with a positive result compared to those with a negative result $\left(r_{z}=-2.9\right)$.

None of the positive patients had a history of other STIs (HIV, HBV, HCV and or syphilis) and only 16 patients (55.2\%) had been requested for testing in the in the year prior to the study.

Finally, for the third goal of the study, a total of 35 double samples (12 of the first void specimen and 23 of genital exudate) were analyzed and compared. A very good concordance $(k=0.8)$ was obtained, with 33 concordant results (12 of them with positive result) and 2 discordant results. Of the 2 discordant results, M. genitalium was detected in vaginal and endocervical exudate with a threshold cycle $>34$ not being detected in the midstream urine samples.

\section{DISCUSSION}

In our study, we obtained an important percentage of patients who benefited from a second diagnosis to rule out STIs. Many studies have demonstrated the cost-effectiveness benefits of implementing screening systems for STIs [5,12], in which the costs of a late or erroneous diagnosis exceed those derived from screening.

Screening of urine samples optimizes diagnosis, especially based on age and gender. The results obtained are consistent with what has been described in the scientific literature, where young women $[4,9,13]$ and men are noted due to the high prevalence of STIs and pregnant women due to the risk they pose to pregnancy and fetus $[10,14]$. The difference in leuko- cyte levels is evidence that this variable is relevant for defining the profile of target patients.

In the use of midstream samples for detection of STIs, we obtained a high level of agreement between the different samples, which reinforces the sensitivity of the test for the diagnosis of STIs, without replacing the genital exudate or the first $20-30 \mathrm{~mL}$ of the urine stream as samples of choice, but as a complementary study.

The main limitation of this study was the small sample size of positive results, which makes a more detailed exploration of the patient's profile difficult. In addition, we do not have complete clinical history data that would allow exploring symptoms as an explanatory variable in future studies. It would also be necessary to expand the sample size in order to establish the true efficacy of the midstream samples of urine in the diagnosis of STIs by qPCR.

Finally, some recommendations can be made to improve future implementation of this screening system. First, it should be applied mainly to the profiles that have been identified as a selected-indicated population. Second, it should be developed a cost-benefit analysis to promote the scaling-up of its use.

In conclusion, this study presents a useful screening system for the detection of STIs that could be integrated in a complementary way into the routine of microbiology laboratories based on the age and sex range of patients.

\section{FUNDING}

This work has been funded by Werfen SLU. for the implementation of qPCRs. The supporting source had no involvement in the design of the study, the preparation of the data or manuscript or the decision to submit for publication.

\section{CONFLICTS OF INTEREST}

The authors declare that they have no conflicts of interest

\section{REFERENCES}

1. Delgado $S$, Garcia-Garrote $F$, Padilla $B$, Rodríguez Gómez JM, Romero B. Diagnóstico microbiológico de la infección bacteriana asociada al parto y al puerperio. 54. Padilla B (coordinator). Procedimientos en Microbiología Clínica. Cercenado Mansilla E, Cantón Moreno R (editors). Sociedad Española de En- fermedades Infecciosas y Microbiología Clínica (SEIMC). 2015.

2. UpToDate. (2019). Retrieved from https://www.uptodate.com/ contents/clinical-manifestations-and-diagnosis-of-chlamydia-trachomatis-infections?search=chlamydia\%20trachomatis\&source=search_resulttselectedTitle=2 141\&tusage_type $=$ de faultetdisplay_rank=2.

3. Recommendations for the laboratory- based detection of Chlamydia trachomatis and Neisseria gonorrhoeae. MMWR Recomm Rep 2014;63(RR-02):1-19. 
4. Wise GJ, Schlegel PN. Sterile pyuria. N Engl J Med. 2015;372(11):1048-1054. doi:10.1056/NEJMra1410052.

5. Goonewardene S, Persad R. Sterile pyuria: a forgotten entity. Ther Adv Urol. 2015;7(5):295-298. doi:10.1177/1756287215592570.

6. Pallawela S, Sonnex C, Burdett J, Cooper D, Nethercott K, Thomas C et al. Testing for 'threads' and leucocyte esterase in first-void urine to exclude the diagnosis of non-specific urethritis in asymptomatic men. Sex Health. 2014;11(3):283-4. doi: 10.1071/SH13190.

7. Ronald RA. Urinary tract infections in adults. En: Tan JS, editor. Experts guide to the management of common infectious diseases.US: American College of Physicians, 2002;229-50

8. PhilaTomas ME, Getman D, Donskey CJ, et al. Over diagnosis of urinary tract infection and under diagnosis of sexually transmitted infection in adult women presenting to an emergency department. J Clin Microbiol 2015;53(8):2686-92. doi: 10.1128/JCM.00670-15

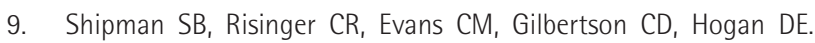
High Prevalence of Sterile Pyuria in the Setting of Sexually Transmitted Infection in Women Presenting to an Emergency Department. West J Emerg Med. 2018;19(2):282-286. doi:10.5811/westjem.2017.12.35605.

10. Nassar FA, Abu-Elamreen FH, Shubair ME, Sharif FA. Detection of Chlamydia trachomatis and Mycoplasma hominis, genitalium and Ureaplasma urealyticum by polymerase chain reaction in patients with sterile pyuria. Adv Med Sci. 2008;53(1):80-86. doi:10.2478/ v10039-008-0020-1.

11. Zboromyrska $Y$, de Cueto López $M$, Alonso-Tarrés $C$, SánchezHellín V. 2019. 14b. Diagnóstico microbiológico de las infecciones del tracto urinario. Zboromyrska $Y$ (coordinator). Procedimientos en Microbiología Clínica. Cercenado Mansilla E, Cantón Moreno R (editors). Sociedad Española de Enfermedades Infecciosas y Microbiología Clínica (SEIMC). 2019.

12. Foxman B. Epidemiology of urinary tract infections: incidence, morbidity, and economic costs. Dis Mon. 2003;49(2):53-70. DOI:10.1067/mda.2003.7.

13. Jones $\mathrm{S}$, Barker $\mathrm{S}$, Athan $\mathrm{E}$, Graves $\mathrm{S}$. The tip of the iceberg: opportunistic screening for Chlamydia trachomatis in asymptomatic patients attending a young people's health clinic reveals a high prevalence - a pilot study. Sex Health. 2004;1(2):115-9. doi: 10.1071/ sh03007.

14. Wynn, $A$, Bristow $C$ C, Cristillo $A D$, et al. Sexually transmitted infections in pregnancy and reproductive health: Proceedings of the STAR sexually transmitted infection clinical trial group programmatic meeting. Sex Transm Dis. 2020;47(1):5-11. doi: 10.1097/ OLQ.0000000000001075 